\title{
PDA Use by Physicians: Where Do They Fit with Emerging Technologies and Use of Electronic Health Records in Office Practices?
}

\author{
Kimberly A. Galt, PharmD, PhD ${ }^{1,2^{*}}$; Kevin T. Fuji, PharmD ${ }^{1,2}$; \\ Andjela Drincic, $\mathrm{MD}^{1,3}{ }^{1}$; James D. Bramble, $\mathrm{PhD}^{1,2}$; Mark V. Siracuse, PharmD, \\ PhD $^{1,2}$; Karen A. Paschal, PT, DPT, MS ${ }^{1,2}$; Amy A. Abbott, PhD, RN $\mathbf{1}^{1,4}$ \\ ${ }^{1}$ Creighton Center for Health Services Research and Patient Safety, Creighton \\ University, Omaha, NE USA \\ ${ }^{2}$ Creighton University School of Pharmacy and Health Professions, Creighton \\ University, Omaha, NE USA \\ ${ }^{3}$ Creighton University School of Medicine, Creighton University, \\ Omaha, NE USA \\ ${ }^{4}$ Creighton University School of Nursing, Creighton University, \\ Omaha, NE USA
}

Submitted September 2011. Accepted for publication November 2011.

\begin{abstract}
This cross-sectional study explores physicians' attitudes and beliefs about the use of personal digital assistant (PDA) in the context of other health information technology (HIT) use and HITbased applications safety in ambulatory care practices. The relationship of PDA use and patient safety is also explored. Ambulatory care physicians in Nebraska and South Dakota were surveyed from July to November of 2007 using a modified Dillman technique. Respondents were in one of three groups: PDA Users (those using a PDA for patient care), Other Technology Users (those not using a PDA, but using other technologies for patient care), and Non-Users (those not using any technology for patient care). PDAs are used by $43 \%$ of responding physicians, who tend to be younger and salaried. PDA Users exposed to PDAs during training continued use in practice. PDA Users believed the device enabled them to provide more efficient and better care, reduce errors, and improve patient safety.
\end{abstract}

Keywords: personal digital assistant (PDA), electronic health record, health information technology, hand held device, ambulatory care

\section{INTRODUCTION}

Handheld computing devices, also known as personal digital assistants (PDAs), were introduced to the market in 1993 with early widespread adoption in 2000 [1]. It has

\footnotetext{
${ }^{*}$ Corresponding Author: Kimberly A. Galt, PharmD, PhD, Creighton University, 2500 California Plaza, Omaha, NE 68178. Phone: (402) 280-4259. Fax: (402) 280-4944. E-mail: kgalt@creighton.edu. Other authors: kfuji@creighton.edu; adrincic@creighton.edu; jdbramble@creighton.edu; marksiracuse@creighton.edu; kpaschal@creighton.edu; amyabbott@creighton.edu.
} 
been estimated that $45-85 \%$ of physicians actively used a PDA in 2005, indicative of increased use in health care delivery by clinicians. It has been shown that clinicians regard PDAs as both feasible to use and convenient, and patients view physicians more positively when they received explanations about why the physician is using the PDA during care [1-4]. PDAs are inexpensive, mobile, and rapidly accessible at the point of care with a multitude of applications. The PDA's entrance into the medical "gadget market" coincided with the wide and rapid adoption of other technologies (e.g., desktops/laptops and tablet personal computers (PCs)). The widespread availability of these health information technologies (HITs) is now followed by the gradual incorporation of electronic health records (EHRs) and associated clinical support tools into health care delivery settings $[5,6]$.

Given the low cost, convenience, comfort and familiarity offered by the PDA, it is possible that its relevance as a technology remains along with other HITs, particularly when we consider the slow adoption of EHRs and associated clinical support tools in both inpatient and outpatient settings [7]. Further, these low-cost, portable devices offer an advantage to practitioners in rural communities where resources and workforce to support an HIT infrastructure are less likely as compared to their counterparts in urban settings [8]. Uses for PDAs in health care delivery include both administrative tasks and some aspects of patient care, such as accessing medical references, data collection/management, patient tracking and medical record management $[1,3,9,10]$. Younger physicians, residents and those working in large and hospital-based practices were most likely to employ PDAs for these uses [1]. Research studies exploring the potential for PDA application have focused on uses for clinical decision support, information access, and e-prescribing [10, 11].

Most research has focused on physicians in training environments, i.e., medical residents, creating a gap in the literature on PDA application among practicing physicians in the ambulatory environment where most health care is delivered in nonacademic settings. This gap especially exists for those physicians and practices in predominantly rural states. A study published in 2006 focused on statewide PDA introduction to family physicians in Florida found a $38.5 \%$ adoption rate amongst those who received training and an opportunity to continue PDA use [12]. Amongst these family physicians, male, younger and urban-based were significantly more likely to use the PDA [12]. The most commonly used PDA functions were: drug referencing $(89.3 \%)$, checking medication interactions $(84.2 \%)$, calendar/other organizing functions $(72.5 \%)$ and accessing medical reference materials $(51.2 \%)$. Only $18.2 \%$ of family physicians using PDAs reported using it for e-prescribing despite this functionality being made available to all. A longitudinal study of PDA use by medical students, residents and staff determined that their reasons for use are to access drug references, medical references and medical calculators; a high rate of acceptance and longitudinal use was observed [13]. Studies about PDA users indicate that they believe PDA use supports clinical decision making, promotes patient safety, and improves productivity and efficiency [14].

With the exception of the studies discussed, there is little information about the role PDAs play in physicians' daily practice, particularly in rural ambulatory settings. Further, there were no published data exploring how PDA use may relate to the use of other emerging computing technologies in the context of the rural ambulatory settings. It is not 
known if PDAs are continuing to be used in medical practices within the context of newer technology introduction over the more recent years, nor how additional technologies are being incorporated and if each technology platform is used in isolation or as integrated components. There is a need to understand ambulatory and rural physicians' attitudes towards current HIT use and how PDA use is incorporated into this framework.

The purpose of this study is to explore the characteristics of physicians' use of PDA in the context of other HIT in ambulatory care practices in the largely rural states of Nebraska and South Dakota. Attitudes and beliefs of PDA users in relationship to technology are described. The findings from this work may benefit those who are responsible for supporting HIT infrastructure systems or making decisions about HIT resources in the rural ambulatory settings. Our long-term goal is to contribute knowledge that assists ambulatory care practitioners and rural communities with improved quality and safety in health care through the use of cost-effective HIT.

\section{METHODS}

\subsection{Study Design and Survey Methodology}

This study was approved by the Creighton University Institutional Review Board for protection of human subjects in research. A cross-sectional survey exploring HIT use was distributed to ambulatory care physicians in Nebraska and South Dakota between July and November 2007. Physicians in both states were asked to self-identify if they maintained an ambulatory care practice and if so, were invited to complete the survey. American Medical Association (AMA) 2008 data indicates 4,334 of the 6,886 physicians licensed in Nebraska and South Dakota maintain an ambulatory care practice [15]. Each state's licensure database served as the primary record source to identify physicians $[16,17]$. Data were supplemented from the Health Professions Tracking Center and the Nebraska Medical Association [18, 19]. In the United States, about $10 \%$ of the physicians practice in rural areas. In comparison, $43 \%$ and $40 \%$ of physicians within each of the states of Nebraska and South Dakota, respectively, practice in rural areas [20]. While nationally, the proportion of the U.S. population that resides in rural areas is $16 \%$, the proportion of rural residents is more than $40 \%$ in Nebraska and 56\% in South Dakota, respectively [21].

The physicians identified from these sources were sent an initial mailing. A cover letter provided instructions for survey completion and return via U.S. mail by facsimile or the provided prepaid envelope. It was distributed three times with a reminder postcard sent before the second mailing via U.S. mail in the provided prepaid envelope or facsimile, and third mailing to non-responders identified in each cycle of distribution over an eight-week period [22]. No incentives were provided to potential respondents. The survey was designed to reduce responder burden following the published guidelines of Dillman, et al [22]. The survey was estimated to take 15-30 minutes to complete. A total of 955 physicians completed and returned surveys of the potential 4,334 , resulting in an overall response rate of $22 \%$.

\subsection{Survey Development}

The survey was developed using items from previous works, published surveys, and new items based on the study's purpose [23-34]. The survey contained psychometrically-developed items designed to assess physicians' attitudes toward HIT 
value and use, as well as items developed to describe physicians' use of various technologies [10]. There were demographic questions and a total of 34 survey items representing six subcategories for this analysis: (a) experience with computing technologies (5 items), (b) compatibility attitudes towards computing technologies (3 items), (c) perceived barriers to use of computing technologies (9 items), (d) emotional attitudes towards computers (8 items), (e) beliefs about computing technologies and safety (4 items), and (f) safety perceptions in daily practice work (5 items). The survey items used in this study were part of a larger instrument with a total of 108 items. These other areas were not directly related to this work. The survey was pilot tested with three physicians for face and content validity. Items were refined to reduce ambiguity and improve readability and ease of completion.

\subsection{Measures/Variables}

We collected categorical and Likert scale measures of self-reported perceptions about HIT and current technologies that respondents were employing. Respondents self-identified with one of three HIT technology groups: PDA Users (using a PDA for patient care), Other Technology Users (using other technologies such as desktop, laptop, or tablet PC but not a PDA), and Non-Users (not using any technology in patient care). Attitude measures were collected on a 5 point Likert scale ranging from "strongly disagree" (1) to "strongly agree" (5). These data were further categorized as either positive or negative attitude, and transformed for analysis. Positive attitudes were associated with "strongly agree" and "agree" responses, while other responses were considered negative.

\subsection{Data Analysis}

Descriptive statistical analysis of demographic characteristics of respondents and their patterns of HIT use was conducted. Data were entered into SPSS software (version 16, SPSS Inc.), cleansed and verified through a quality assurance process applied to the data records. Survey respondent data were deidentified and linkable only through a unique identification number assigned to the respondent initially with the first survey distribution cycle. Chi-square analyses were conducted to examine the relationship of HIT group to various attitudes toward use of HIT in practice. For all statistical tests, a two-sided p-value $<0.05$ was adopted as the significance criteria.

\section{RESULTS}

\subsection{Physician and Practice Characteristics}

Approximately, one-fourth of the physicians who maintain an ambulatory practice in the states of Nebraska $(n=612)$ and South Dakota $(n=343)$ responded to the survey. Respondents were predominately male $(73.8 \%)$, White/Caucasian $(91 \%)$, and had an average age of 50 years old. Age and gender agreed with the distribution patterns reported for practicing physicians in each state. Most respondents worked in freestanding practices $(62.6 \%)$ and $57.4 \%$ of the respondents classified themselves as

primary care physicians (i.e., General/Family Practice, Internal Medicine, Pediatrics, or Obstetrics/Gynecology). Those not classified as a primary care physician indicated that they were in specialty ambulatory care practices. The distribution of respondents by these demographic characteristics was comparable to the national data generated from the AMA workforce statistics on physicians in the United States [14]. 
Of the 955 respondents, $40.4 \%$ were in the PDA User group. To understand PDA User characteristics, they were compared to Other Technology Users and Non-Users. There were 412 physicians (43.5\%) in the Other Technology User group and 153 (16.1\%) physicians in the Non-User group. A comparison of the respondents between Nebraska and South Dakota revealed no statistically significant difference in the distribution of technology use $\left(\chi^{2}=3.133, \mathrm{p}=0.209\right)$. As such, we combined the physicians' responses from both states for the analyses. More demographic data on those that responded can be found in Table 1.

Table 1. Demographics of survey responders $(n=955)$

Physician Characteristics

Return rate
Sex
Mean age
Mean years in practice

Race

\section{Practice Characteristics}

$\begin{array}{rc}\text { Free-standing practices } & 62.6 \% \\ \text { Medical group } & 17.8 \% \\ \text { Medical school } & 11 \% \\ \text { Rural health clinics } & 5.6 \% \\ \text { Federally qualified health centers } & 3 \%\end{array}$

Practice Type

$$
\begin{array}{r}
\text { General/family practice } \\
\text { Internal medicine } \\
\text { Pediatrics } \\
\text { Obstetrics/gynecology } \\
\text { Ambulatory specialty care }
\end{array}
$$

$\begin{array}{rr}\text { Nebraska } & 64.1 \% \\ \text { South Dakota } & 35.9 \% \\ & \\ \text { Male } & 73.8 \% \\ \text { Female } & 26.2 \%\end{array}$

$\begin{aligned} \text { Male } & 52 \text { years old } \\ \text { Female } & 44 \text { years old }\end{aligned}$

$\begin{aligned} \text { Male } & 20 \text { years } \\ \text { Female } & 12 \text { years }\end{aligned}$

$\begin{array}{rc}\text { White/Caucasian } & 91 \% \\ \text { Asians } & 4.4 \% \\ \text { Hispanic/Latino } & 2.2 \% \\ \text { Black/African American } & 1 \% \\ \text { Hawaiian Islander or } & >1 \% \\ \text { American/Alaskan Indian } & \end{array}$

$32.4 \%$

$8.2 \%$

$8.5 \%$

$8.3 \%$

42.6 


\subsection{PDA User Characteristics}

PDA Users followed the gender and racial distribution of the overall respondents - 74\% male and 90\% Caucasian/White. On average, PDA Users were the youngest age group (47.6 years), followed by Other Technology Users (50 years) and Non-Users (54.6 years $),(r=.226, \mathrm{p}<0.001)$. These ages corresponded similarly to average years in practice for each group of 16.3, 18.2 and 22.6 years, respectively $(r=.189, \mathrm{p}<0.001)$. A higher proportion of the PDA Users and Other Technology Users groups were employed physicians (51.9\% and 45\%, respectively) compared to Non-Users $(66 \%$ owner or part-owner in practice) $\left(\chi^{2}=35.444, \mathrm{p}<0.001\right)$.

We found a significant relationship between HIT group and prior experience with information technology. Current PDA Users were more likely than Other Technology Users and Non-Users to have previous experiences with PDA, tablet PC, laptop, and desktop computers (see Table 2). Overall, $77.3 \%$ of current PDA Users used a PDA in prior practice/training. No gender differences were observed.

Table 2. Physician's prior experience with specific computer technologies

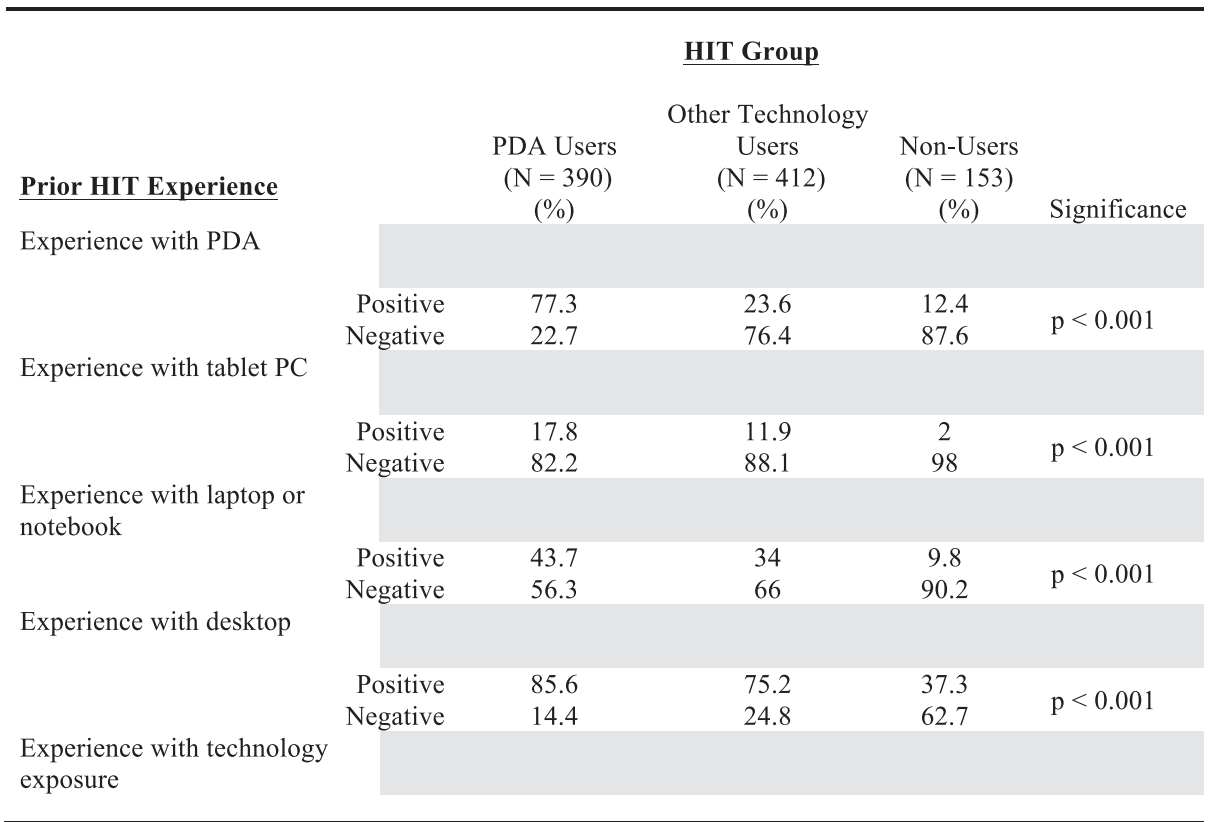

\subsection{How PDAs are Presently Used} 3.3.1. PDA Users and HIT Use PDAs are used by $43 \%$ of respondents. All PDA Users reported using a PDA with at least one additional computing device, i.e., none of the respondents used only PDAs in the practice setting. PDA Users reported using additional portable devices as opposed 
to fixed desktop computers. For example, $13.6 \%$ of PDA Users also used tablet PCs and $45.4 \%$ also used laptop computers. PDA Users demonstrate they have integrated other portable devices into daily practice.

\subsubsection{Compatibility with practice}

There was a significant relationship between HIT Group and the physician's attitude towards the PDAs compatibility (see Table 3). Nearly half of PDA Users believe PDA use is compatible with all aspects of their practice, and two-thirds felt PDAs fit well with their practice style and the way they like to practice. Most respondents in the other two groups did not find that PDAs fit their practice style or the way they liked to practice. PDA Users saw, on average, an equal number of patients weekly as their colleagues using other technologies (80 patients vs. 77 patients). In comparison, more PDA Users believed that this technology improves efficiency compared to the other groups. However, Non-Users reported seeing more patients weekly (89 patients).

\section{Table 3. Compatibility attitudes toward PDAs in relationship to computing technology use}

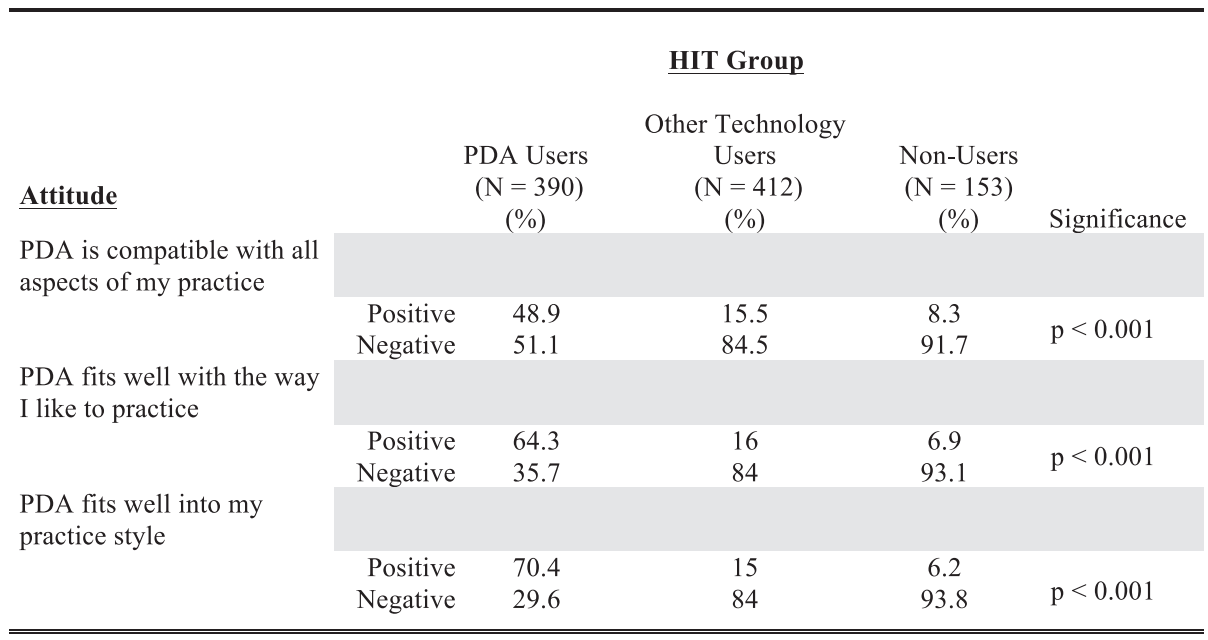

\subsubsection{PDA use and technology use perceptions}

Physicians using PDAs reported fewer barriers to PDA and technology use. PDA Users reported less difficulty seeing when working with small computing devices, feeling the buttons, and using a small computing device touch screen than the other groups (see Table 4). Fewer PDA Users regard time to use the PDA as a barrier compared to the other groups. There is a significant relationship between HIT use and attitudes and beliefs towards computers and computer-based learning (see Table 5). PDA Users like computers, like learning on computers, and believe computers facilitate learning more than Other Technology Users and Non-Users. They were least likely to find computers 
unfriendly; feel uncomfortable, aggressive, or hostile towards computers; or find computers frightening.

Table 4. Perceived barriers in relationship to computing technology use

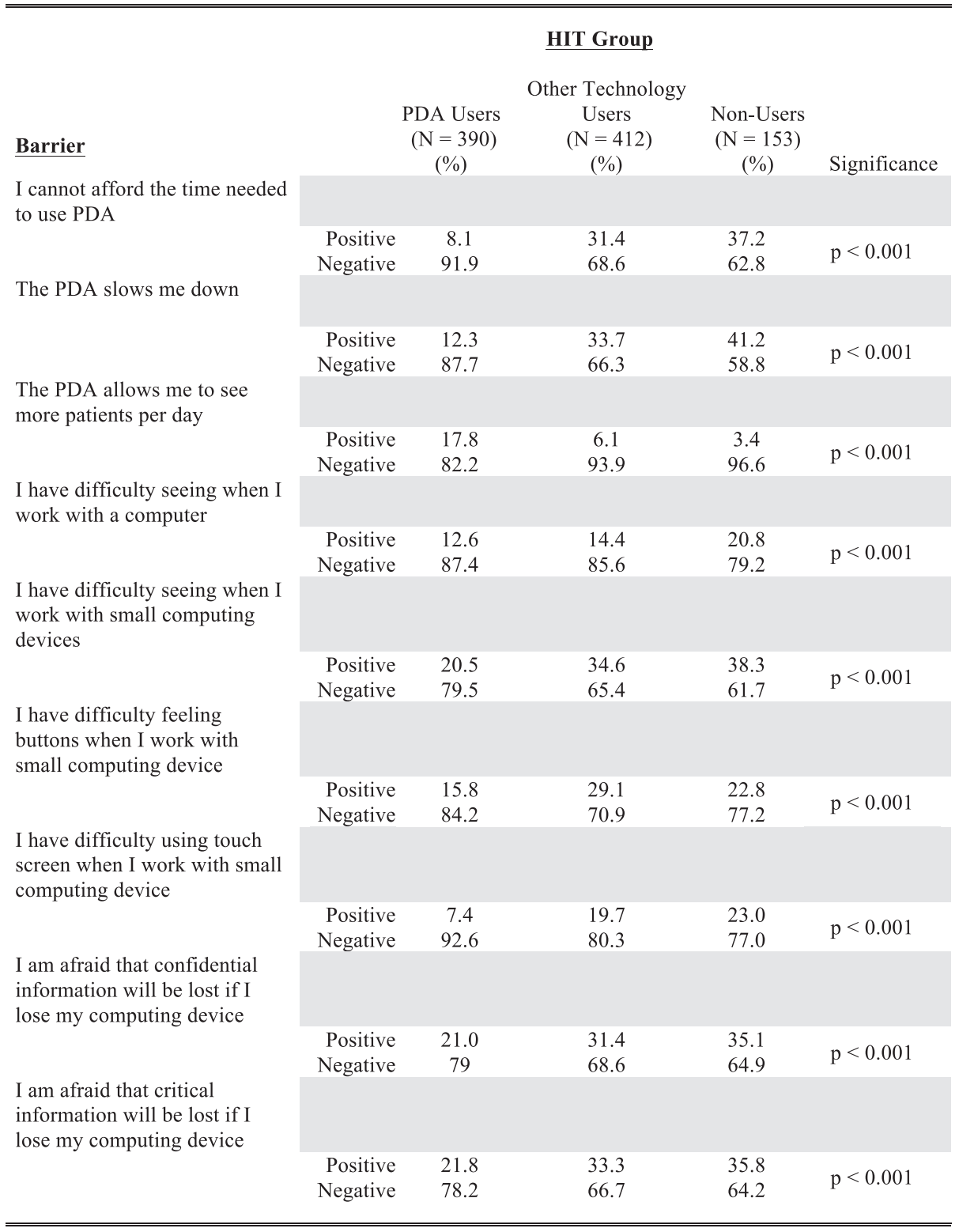


Table 5. Physician's attitudes towards computers

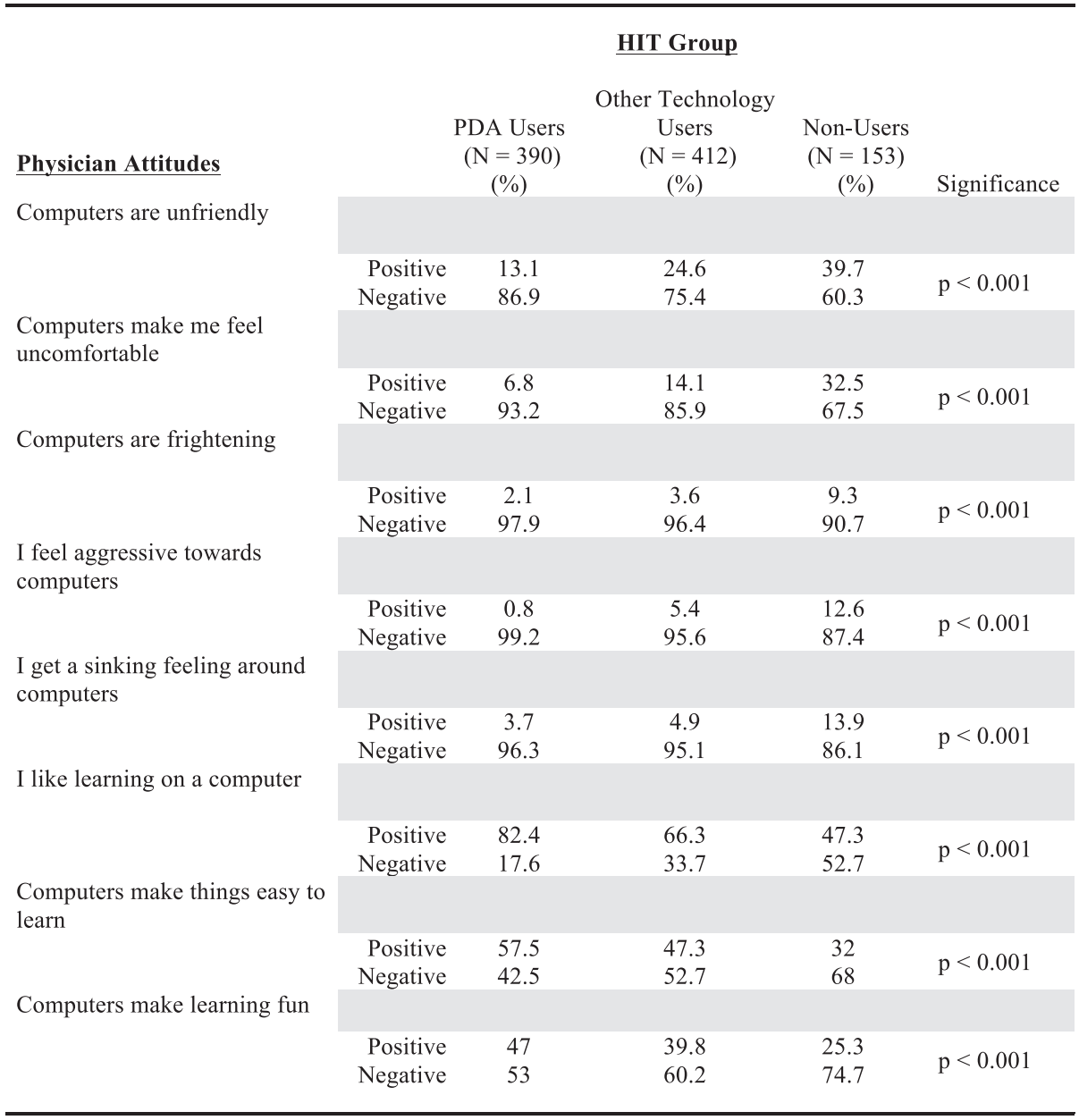

\subsection{Role of PDA in the Context of Newer Computing Technologies}

\subsubsection{PDA Users and EHRs}

Those who have prior PDA use experience are more likely to be using an EHR now or plan to implement an EHR in the future. One-third of PDA Users have an EHR in their practice, with $74 \%$ having prior EHR experience. The majority of PDA Users (58\%) have planned to implement an EHR and only $10.5 \%$ did not plan to implement an EHR. This is in stark contrast to Non-Users, $43 \%$ of whom did not plan to implement an EHR. Compared to their Non-User counterparts, PDA Users reported more daily and weekly use of computing devices of any type, including with the use of an EHR, to view diagnostic test results $(73.3 \%$ vs. $57 \%)$, look up drug references $(77.7 \%$ vs. $34.3 \%)$ and print patient education materials (37.1\% vs. $22.2 \%)$. 


\subsubsection{Computer Use, Quality of Care and Patient Safety}

More than other groups, PDA Users believed computer use reduced errors in practice and improved patient safety. A focus on error prevention was evident in the PDA User group's belief that PDA-generated prescriptions are more accurate and complete (see Table 6).

Table 6. Physician's beliefs about computer technologies and safety in relation to computer technology use

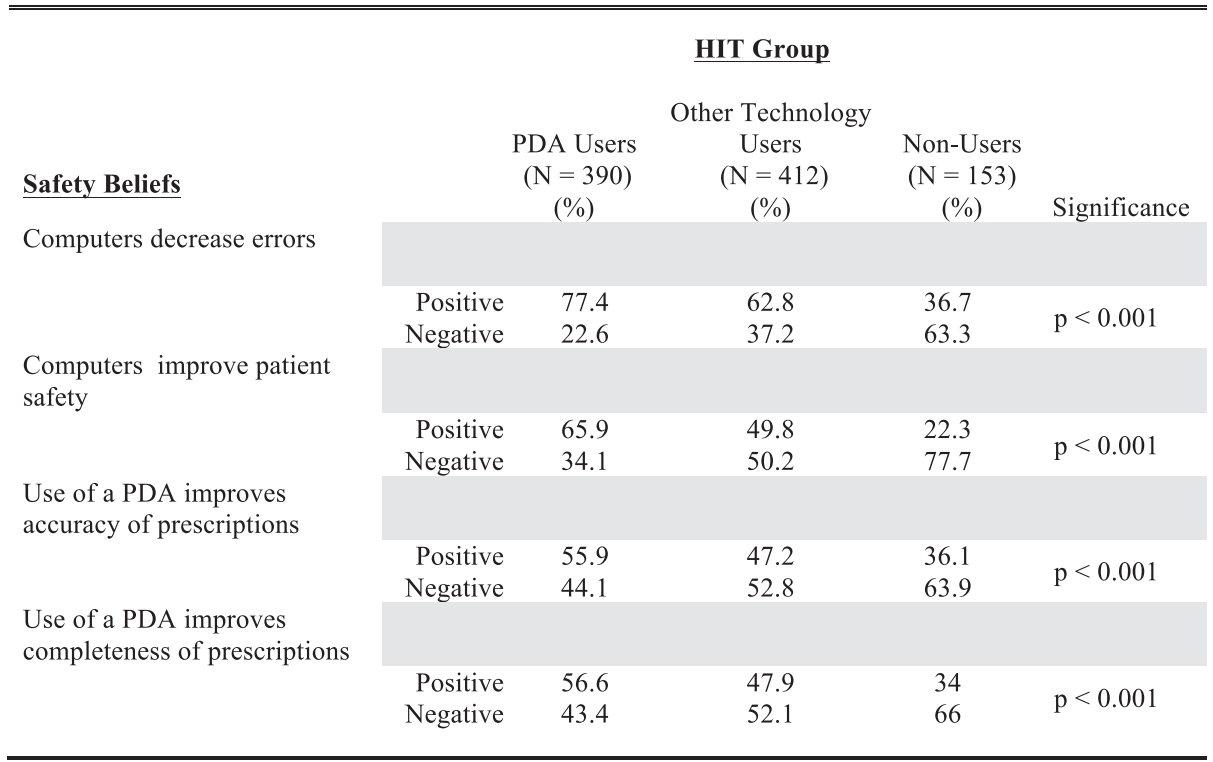

The PDA allows for more completeness and better accuracy due to the ability to access drug information and potentially generate prescriptions. Use of PDAs for generating prescriptions was relatively uncommon - only $6 \%$ of PDA Users reported use for this purpose. PDA Users and Other Technology Users reported using other forms of technology to generate prescriptions: tablet PCs (6.4\%) and desktop/laptop computers $(23.1 \%)$.

Five patient safety indicators in daily clinical practice were explored in relationship to technology use. Respondents were asked to indicate if they experienced any of the problems at least once in the past three months of their practice: (1) clinical information unavailable at the time of the visit, (2) a test or procedure had to be repeated because information was unavailable at the visit, (3) a patient received the wrong drug, dose, or experienced a preventable error, (4) a patient follow-up was missed for an abnormal test result, and (5) a patient had a problem after hospital discharge because the physician did not receive needed information from the hospital in a timely manner. While researchers have shown PDA use prevents some medical errors and improves information flow, PDA Users in this study reported seeing or experiencing more error incidents than the 
other two groups. Statistically significant relationships were detected between the HIT group and the patient safety experiences reported (see Table 7) [35-37].

Table 7. Safety perceptions of respondents

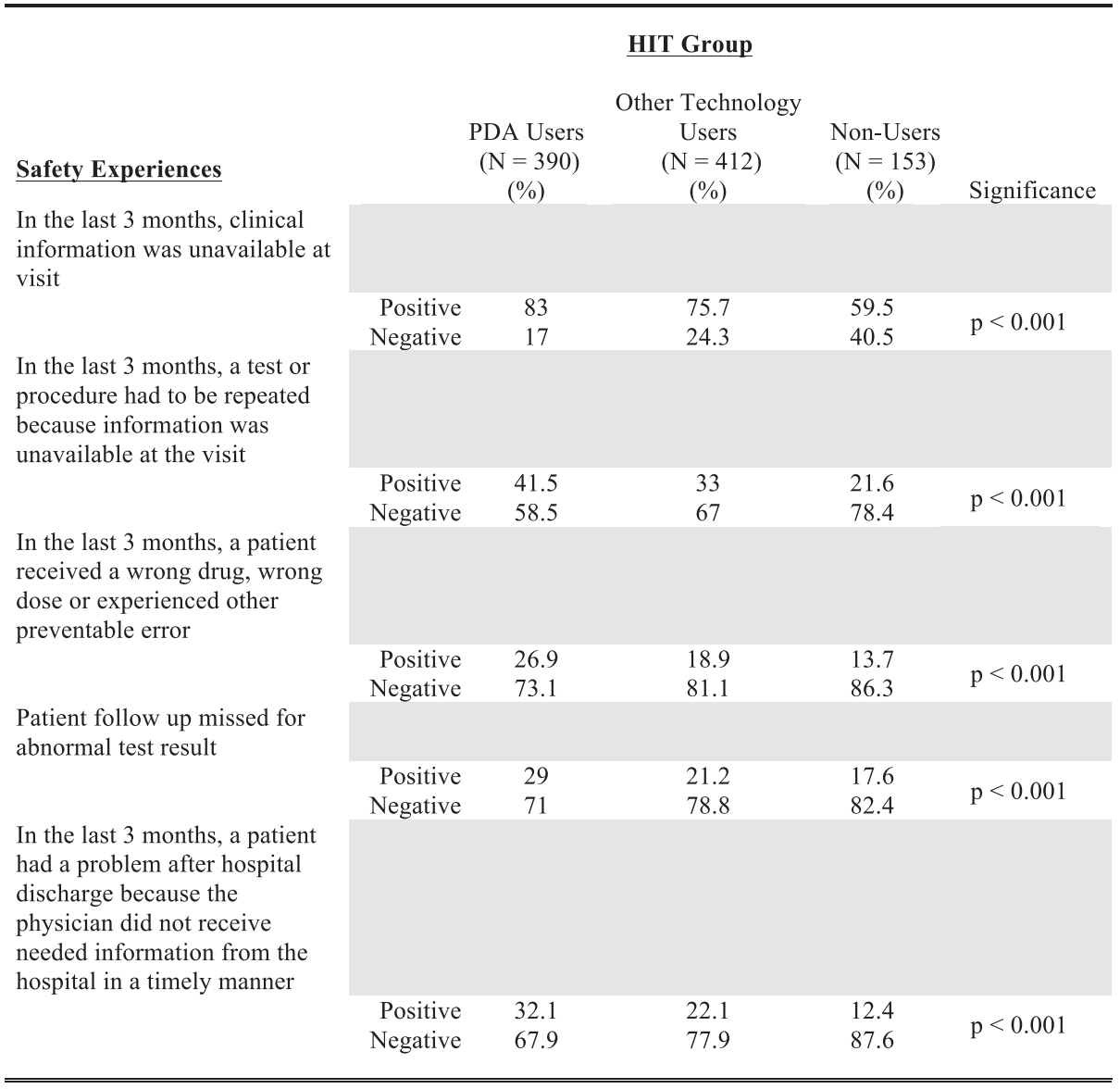

\section{DISCUSSION}

PDAs appear to occupy a substantial role in the daily practice of many physicians. The PDA has not replaced other computing devices. Rather, the PDA Users used at least one additional computing device and portable technology more frequently than Other Technology Users. Similar to other studies, this study's results show that PDA Users are often younger physicians, less likely to fully own their practices, and more likely salaried employees. Although other research suggests male physicians more frequently report using PDAs [1, 12], no significant differences in use by gender were found in this study. 
PDA use patterns suggest that familiarity with computing devices through early exposure to specific technology is associated with increased use later in one's career. PDA Users exposed to PDAs during training actively use the technology in their practices. Current PDA Users were also actively exposed to HIT and its various forms in patient care. In general, PDA Users like computers. This positive attitude toward technology appears to be a prerequisite for active PDA use in practices.

PDA Users are very interested in EHRs. A significant proportion of physicians who have electronic records still use PDAs, implying this technology has value for EHR users. The intent to implement EHRs is mostly higher in the PDA User group than the Non-User group. Over $40 \%$ of Non-Users are not considering EHR implementation.

Physicians using PDAs believe they improve patient safety and allow them to provide more efficient care. PDA Users have more faith in technology and believe computer use reduces errors in practice. This is consistent with previous work describing predictors of PDA adoption [9]. PDA Users reported seeing more errors, data missed and follow-up care omitted. This may reflect PDA Users' heightened vigilance and sensitivity toward medical errors. They are concerned with safety and more likely to notice when patient safety is threatened. It is not known whether actual medical error incidents are truly higher in the PDA User group than in the other groups. PDA Users are concerned with safety and quality of care, reflected in their strong belief that PDA-generated prescriptions are more accurate and complete than non-PDAgenerated prescriptions.

These study results about physicians' behavior with PDAs are consistent with both the Technology Acceptance Model (TAM) theory and the Innovations Diffusion Theory [38 - 40]. The TAM theory was developed specifically for explaining and/or predicting user acceptance of computer technology [41]. It postulates that computer acceptance behaviors are influenced by two particular beliefs, perceived usefulness and perceived ease of use. Perceived usefulness is the prospective user's subjective probability that using a specific application system will increase job performance. Perceived ease of use refers to the degree to which the prospective user expects using the target system to be free of effort. Both beliefs are observed in the physicians of the PDA User group: the familiarity with technology through prior experience (perceived ease of use) and the perceived value of technology to patient safety. Results from this study also support the concept of compatibility, one of seven constructs in the Innovations Diffusion Theory $[39,40]$. Compatibility is defined as "the degree to which an innovation is perceived as being consistent with the existing values, needs and past experiences of potential adopters"[42]. All constructs mentioned are potential predictor's of physician uptake and use of HIT [43].

Physicians who chose not to use PDAs were not concerned with cost or small buttons (ease of use). They were not exposed to this technology, did not perceive it to be potentially useful (perceived usefulness), and did not think it would improve patient care or safety. Whether or not these perceptions are true, they remain a significant barrier to technology adoption. Compatibility was a key construct related to PDA uptake and use. After financial barriers for EHR adoption are addressed, if physicians do not view a technology as useful, easy to use and compatible with their work environment, it will not be embraced. While EHR adoption has been set as a national 
priority with the intention of improving patient care, in a recent survey, only $4 \%$ of respondents reported having a fully-functional electronic-records system, where $13 \%$ had a basic system [5]. In this study, physicians lacking access to an electronic record system commonly cited capital cost as an adoption barrier (66\%). EHR cost seems to be an obstacle impossible to overcome without a government intervention. While cost is the most prevalent concern, is it the most significant? If cost is not the most significant barrier, can a study of PDA adoption help us understand and overcome other significant barriers to EHR adoption? There is a need for further intervention studies, action research and studies of various health care groups to identify appropriate use and applications of value [2].

\subsection{Limitations}

The area of study involved a two state region that have a large proportion of physicians practicing in rural communities. Rural communities are less likely to have high speed Internet and other technologies available to their urban counterparts. Thus, these results cannot be generalized to states with a larger proportion of urban communities. Replication of the study among more urban states is needed to overcome this limitation to the study.

There is the potential for response bias due to the non-random nature of those who responded to the survey. Recognizing the relatively low response rate, we realize that non-response bias poses a threat to this study. Prior research has shown that respondents that respond later to a survey, after many more stimuli, e.g., reminders, are expected to be similar to non-respondents $[44,45]$. When non-response bias was explored in a related research study of these same data, we found that late responders were similar to early responders with regard to their EHR adoption status, i.e., adopters vs. non-adopters. Thus we believe non-response bias in this study to be minimized [46].

\subsection{Future Research}

The effect of PDA use on the quality and safety of patient care or patient safety outcomes have not been well studied. This study's findings suggest differences warranting further investigation. Future research is needed to evaluate the efficiency of performing specific tasks using PDA technology in the context of EHR adoption. While EHR use is low at present, there is a clear momentum of growth.

Further studies must be conducted to better clarify and quantify the benefits of PDA use to best inform decision-makers and consumers about PDA adoption. This is especially crucial as the use of smart phones increases by both physicians and consumers [11]. It is estimated that two-thirds of physicians and nearly half of all Americans owned smart phones [47]. PDAs are often viewed as pre-cursors to smartphones, and as such, findings from this study and suggestions for future research have the potential to provide a framework for the continued use of this technology and its many health care applications within the context of increasing adoption and use of HIT [47]. 


\section{CONCLUSION}

Among our physician respondents, $43 \%$ reported using a PDA along with at least one other form of HIT. PDA Users were also interested in using EHRs. PDA Users believed computer use reduced errors in practice and improved patient safety; they also reported seeing or experiencing more error incidents than physicians who did not use PDAs.

Compatibility, ease of use, usefulness and the perceived improvement in patient safety are major factors associated with continued PDA use by physicians. Additionally, this study showed that prior HIT use is strongly related to future HIT use. It is inevitable that HIT will continue to evolve and grow within healthcare as evidenced by the adoption of EHRs as a national priority. Thus, it is increasingly important that health care providers have an opportunity to use handheld mobile computing devices and receive HIT exposure and training early. This will prepare physicians to fully utilize the available technology and help them deliver high quality and safe care throughout their careers.

\section{ACKNOWLEDGEMENTS}

This project was supported by the grant "Enhancing Clinical Practices through the Adoption of Health Information Technology in Nebraska" through the Nebraska Medical Association and the Creighton Health Services Research Program grant no. 5P20 HS015816-02 Building Research Infrastructure Capacity from the Agency for Healthcare Research and Quality (AHRQ).

The authors of this paper would like to thank Jamie Steemken for her technical assistance, Ted Kasha for his assistance with data analysis and Trenton Keim for his assistance in editing portions of this manuscript.

\section{CONFLICT OF INTEREST: None.}

\section{REFERENCES}

[1] Garritty C, El Emam K. Who's using PDAs? Estimates of PDA use by health care providers: systematic review of surveys. Journal of Medical Internet Research. 2006; 8(2):e7.

[2] Lindquist AM, Johansson PE, Petersson GI, Saveman BI, Nilsson GC. The use of personal digital assistant (PDA) among personnel and students in health care: a review. Journal of Medical Internet Research. 2008; 10(4):e31.

[3] Baumgart D. Personal digital assistants in health care: experienced clinicians in the palm of your hand? Lancet. 2005; 366(9492):1210-1222.

[4] McCord G, Pendleton BF, Schrop SL, Weiss L, Stockton L, Hamrich LM. Assessing the impact on patient-physician interaction when physicians use personal digital assistants: a Northeastern Ohio Network (NEON®) study. The Journal of the American Board of Family Medicine. 2009; 22(4):353359.

[5] DesRoches CM, Campbell EG, Rao SR, Donelan K, Ferris TG, Jha A, Kaushal R, Levy DE, Rosenbaum S, Shields AE, Blumenthal D. Electronic health records in ambulatory care - a national survey of physicians. New England Journal of Medicine. 2008; 359(1):50-60.

[6] Jha AK, DesRoches CM, Campbell EG, Donelan K, Rao SR, Ferris TG, Shields A, Rosenbaum S, Blumenthal D. Use of electronic health records in U.S. hospitals. New England Journal of Medicine. 2009; 360(16):1628-1638.

[7] Uslu A, Stausberg J. Value of the electronic medical record for hospital care: a review of the literature. Journal of Healthcare Engineering. 2011; 2(3):271-83. 
[8] Committee on The Future of Rural Health Care - Institute of Medicine of the National Academies. Quality Through Collaboration: The Future of Rural Health Care. The National Academies Press, Washington DC, 2004.

[9] Fischer S, Stewart TE, Mehta S, Wax R, Lapinsky SE. Handheld computing in medicine. Journal of American Medical Informatics Association. 2003; 10(2):139-149.

[10] Galt KA, Siracuse MV, Rule AM, Clark BE, Taylor W. Physician use of hand-held computers for drug information and prescribing. AHRQ Advances in Patient Safety: From Research to Implementation (serial on CD-ROM). 2005; 4:93-108.

[11] Ara A, Salibian BS, Thomas S. Smartphones in surgery. Journal of Healthcare Engineering. 2011; 2(4):473-486.

[12] Menachemi N, Perkins R, Durme DJ, Brooks R. Examining the adoption of electronic health records and personal digital assistants by family physicians in Florida. Informatics in Primary Care. 2006; 14(1):1-9.

[13] Stephens MD, Waechter D, Williams PM, Williams AL, Yew KS. Institutional support for handheld computing: clinical and educational lessons learned. Medical Reference Services Quarterly. 2010; 29(1):28-36.

[14] Vogel EW, Gracely EJ, Kwon Y, Maulitz RC. Factors determining the use of personal digital assistants among physicians. Telemedicine and e-Health. 2009; 15(3):270-276.

[15] Smart DR, Sellers J. Physician Characteristics and Distribution in the U.S., American Medical Association, Chicago, 2008.

[16] Nebraska Health and Human Services System, http://www.hhs.state.ne.us/. Accessed July 26, 2010.

[17] South Dakota Department of Health, http://www.state.sd.us/doh/. Accessed July 30, 2007.

[18] University of Nebraska Medical Center Health Professions Tracking Center. http://www.unmc.edu/hptc/. Accessed June 28, 2010.

[19] Nebraska Medical Association. http://www.nebmed.org. Accessed June 28, 2010.

[20] Support Services Division of Nebraska Health and Human Services System. Rural 2010 Health Goals and Objectives for Nebraska. http://www.hhs.state.ne.us/puh/oph/docs/Rural-2010.pdf. Accessed August 8, 2011

[21] Rural Policy Research Institute. Demographic and Economic Profile South Dakota - updated June 2006. http://www.rupri.org/Forms/SouthDakota.pdf. Accessed August 8, 2011.

[22] Dillman DA. Mail and Internet Surveys: The Tailored Design Method, $2^{\text {nd }}$ ed., John Wiley \& Sons, New York, 2005.

[23] Center for Disease Control National Center for Health Statistics. http://www.cdc.gov/namcs/. Accessed July 26, 2010.

[24] Survey of Kentucky Ambulatory Network Members' Use of Information Technology. 2004.http://healthit.ahrq.gov/portal/server.pt/gateway/PTARGS_0_1248_874955_0_0_18/kentuckya mbulatorynetwork_officemanagersurvey.pdf. Accessed July 26, 2010.

[25] Miller R. Summary report: 2002 medical group office management systems survey. Journal of Medical Practice Management. 2003;18(4):207-210.

[26] The Commonwealth Fund. 2003 National Survey of Physicians and Quality of Care. http://www.commonwealthfund.org/ /media/Files/Surveys/2003/2003\%20National\%20Survey\%20of $\% 20$ Physicians\%20and\%20Quality\%20of\%20Care/2003_nationalsurvey_physicians\%20qualitycare $\% 20$ pdf.pdf. Accessed July 26, 2010.

[27] The Commonwealth Fund. 2001 Health Care Quality Survey. http://www.commonwealthfund.org/ /media/Files/Surveys/2001/2001\%20Health\%20Care\%20Qualit y\%20Survey/qualitysurvey_2001_questionnaire\%20pdf.pdf. Accessed July 26, 2010.

[28] The Commonwealth Fund. 2000 International Health Policy Survey of Physicians. http://www.commonwealthfund.org/ /media/Files/Surveys/2000/2000\%20\%20International\%20Heal th\%20Policy\%20Survey\%20of\%20Physicians/Internatlsurvey_physicians_2000\%20pdf.pdf. Accessed July 26, 2010. 
[29] Medical Records Institute, Seventh Annual Survey of Electronic Health Record Trends and Usage for 2005. http://www.ehto.org/2006/US\%20Medical\%20Records\%20Institute\%20\%20Results\%20of\%20the\%20EHR\%20global\%20survey\%20in\%202005.pdf. Accessed July 26, 2010.

[30] Certification Commission for Healthcare Information Technology. Final Ambulatory Functionality Criteria for 2007 Certification of Ambulatory EHRs. http://www.cchit.org/sites/all/files/CCHITAmbFUNCTIONALITY2007.pdf. Accessed July 26, 2010.

[31] Medical Group Management Association. Assessing Adoption of Effective Health Information Technology Questionnaire. http://www.mgma.com/WorkArea/mgma_downloadasset.aspx?id=292. Accessed July 26, 2010.

[32] Community Clinics Initiative. 2005 Information Management Assessment Survey - Executive Director Version.

http://healthit.ahrq.gov/portal/server.pt/gateway/PTARGS_0_1248_811156_0_0_18/CCI_ED_survey _2005.pdf. Accessed July 26, 2010.

[33] Community Clinics Initiative. 2005 Information Management Assessment - Medical Director Survey. http://healthit.ahrq.gov/portal/server.pt/gateway/PTARGS_0_811158_0_0_18/CCI_MD_survey_200 5.pdf. Accessed July 26, 2010.

[34] Loomis GA, Ries JS, Saywell RM, Thakker NR. If electronic medical records are so great, why aren't family physicians using them? The Journal of Family Practice. 2002; 51(7):636-641.

[35] Healthcare Change Institute. Study of Technology Adoption in California Medical Groups, IPAs and Community Clinics.

http://www.chcf.org/ /media/Files/PDF/S/StudyofTechnologyAdoptionMedGroups.pdf. Accessed June 28, 2010.

[36] Berner ES, Houston TK, Ray MN, Allison JJ, Heudebert GR, Chatham WW, Kennedy JI, Glandon GL, Norton PA, Crawford MA. Improving ambulatory prescribing safety with a handheld decision support system: a randomized controlled trial. Journal of American Medical Informatics Association. 2006; 13(2):171-179.

[37] Galt KA, Rule A, Clark BE, Bramble JD, Taylor W, Moores KG. Best practices in medication safety - areas for improvement in the primary care physician's office. AHRQ Advances in Patient Safety: From Research to Implementation (serial on CD-ROM). 2005; 1:101-129.

[38] Fishbein M, Ajzen I. Belief, Attitude, Intention and Behavior: An Introduction to Theory and Research. Addison-Wesley, Reading, MA, 1975.

[39] Rogers EM. Diffusion of Innovations. 4th ed. The Free Press, New York, 1995.

[40] Venkatesh V, Davis FD. A theoretical extension of the technology acceptance model: four longitudinal field studies. Management Science. 2000; 46(2):186-204.

[41] Davis FD. Perceived usefulness, perceived ease of use and user acceptance of information technology. MIS Quarterly. 1989; 13(3):319-340.

[42] Moore GC, Benbasat I. Development of an instrument to measure the perceptions of adopting an information technology innovation. Information Systems Research. 1991; 2(3):192-222.

[43] Galt KA, Rule A, Taylor W, Siracuse M, Bramble JD, Rich EC, Young W, Clark B, Houghton B. Impact of personal digital assistant devices on medication safety in primary care. AHRQ Advances in Patient Safety: From Research to Implementation (serial on CD-ROM). 2005; 3:247-263.

[44] Richiardi L, Boffetam P, Merlett F. Analysis on non response bias in a population-based case control study on lung cancer. Journal of Clinical Epidemiology. 2002; 55(10):1033-1040.

[45] Armstrong JS Overton TS. Estimating non response bias in mail surveys. Journal of Marketing Research. 1977; 14(3):396-402.

[46] Bramble JD, Galt KA, Siracuse MV, Abbott AA, Drincic A, Paschal KA, Fuji KT. The relationship between physician practice characteristics and physician adoption of electronic health records. Health Care Management Review. 2010; 35(1):55-44.

[47] Platt, A. Put a PDA in your practice for easy access to current medical information. Journal of the American Academy of Physician Assistants. 2009; 22(5):40-44. 


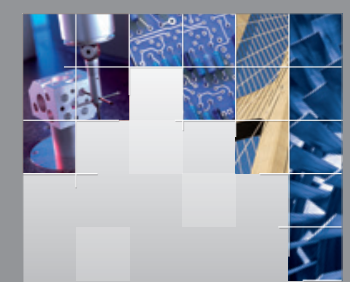

\section{Enfincering}
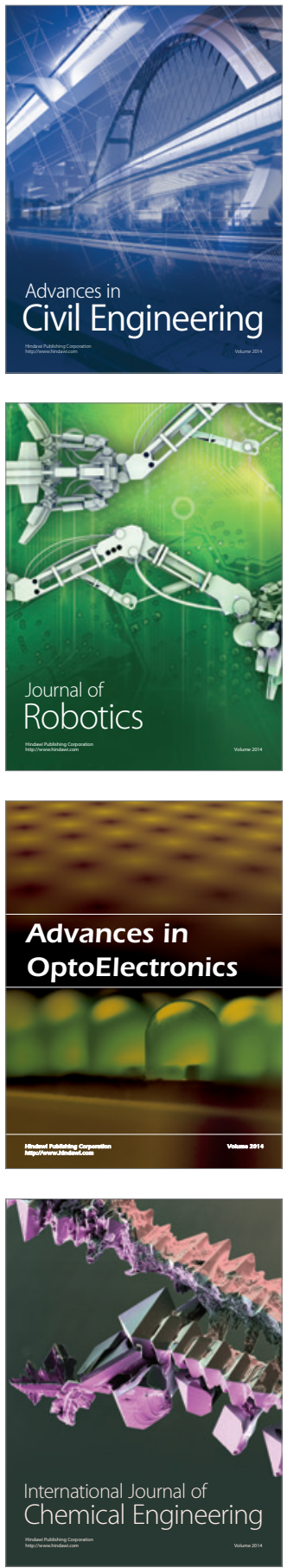

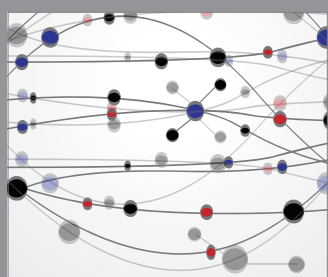

The Scientific World Journal

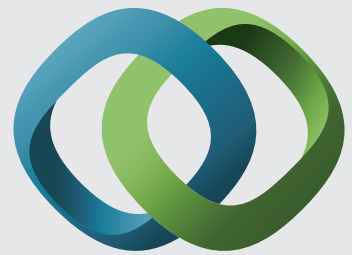

\section{Hindawi}

Submit your manuscripts at

http://www.hindawi.com
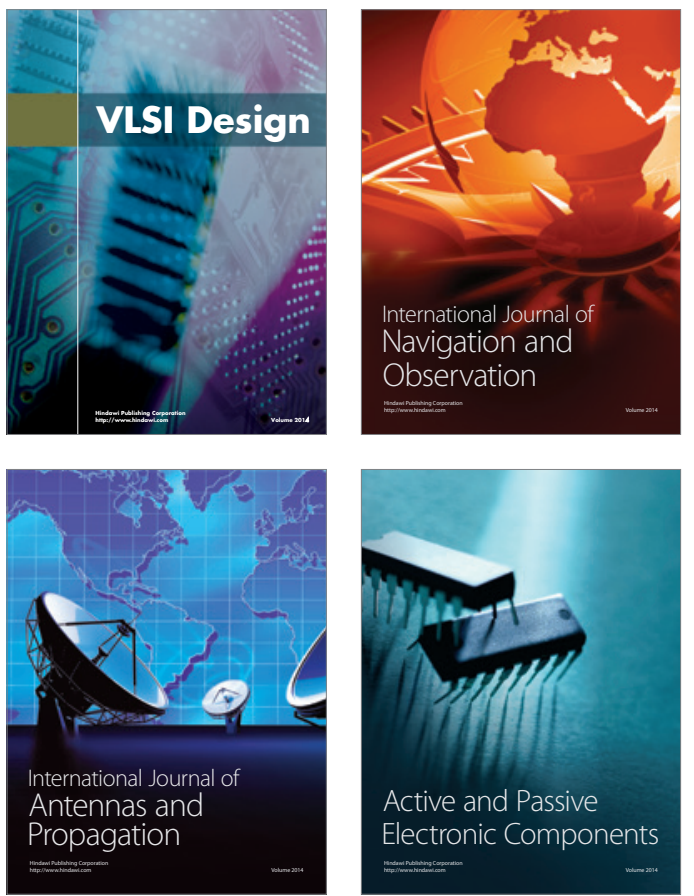
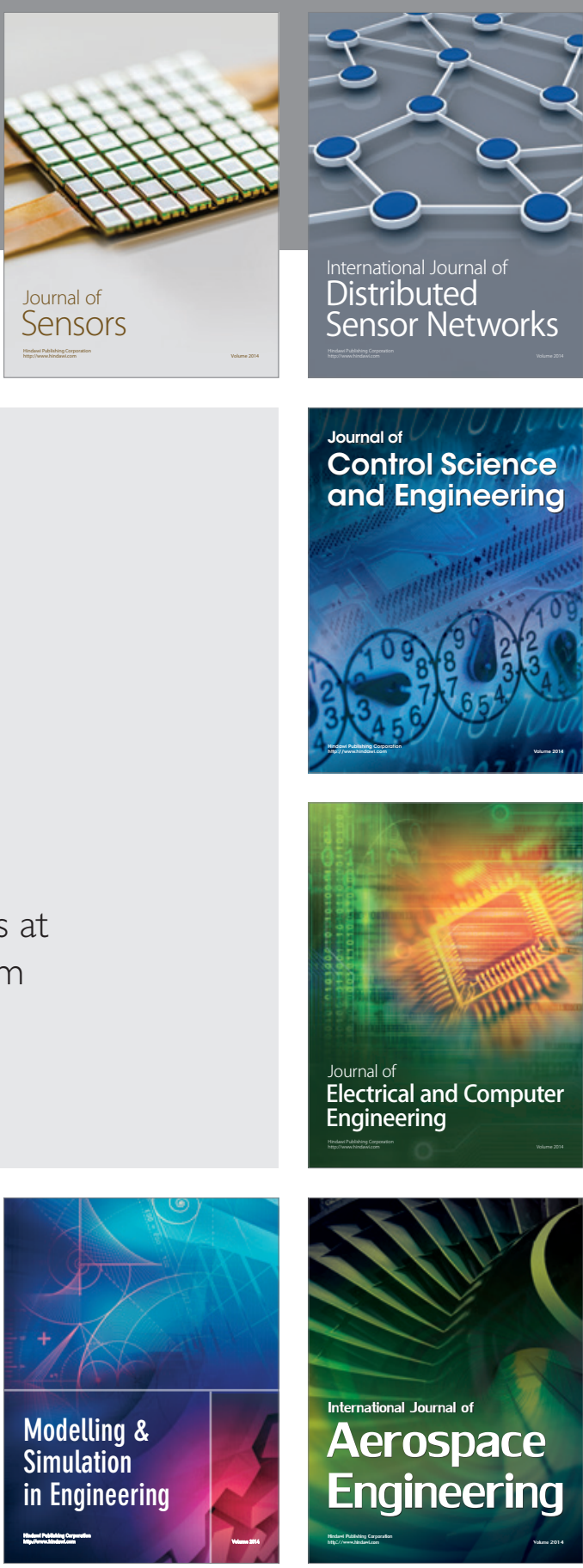

International Journal of

Distributed

Sensor Networks

Journal of

Control Science

and Engineering
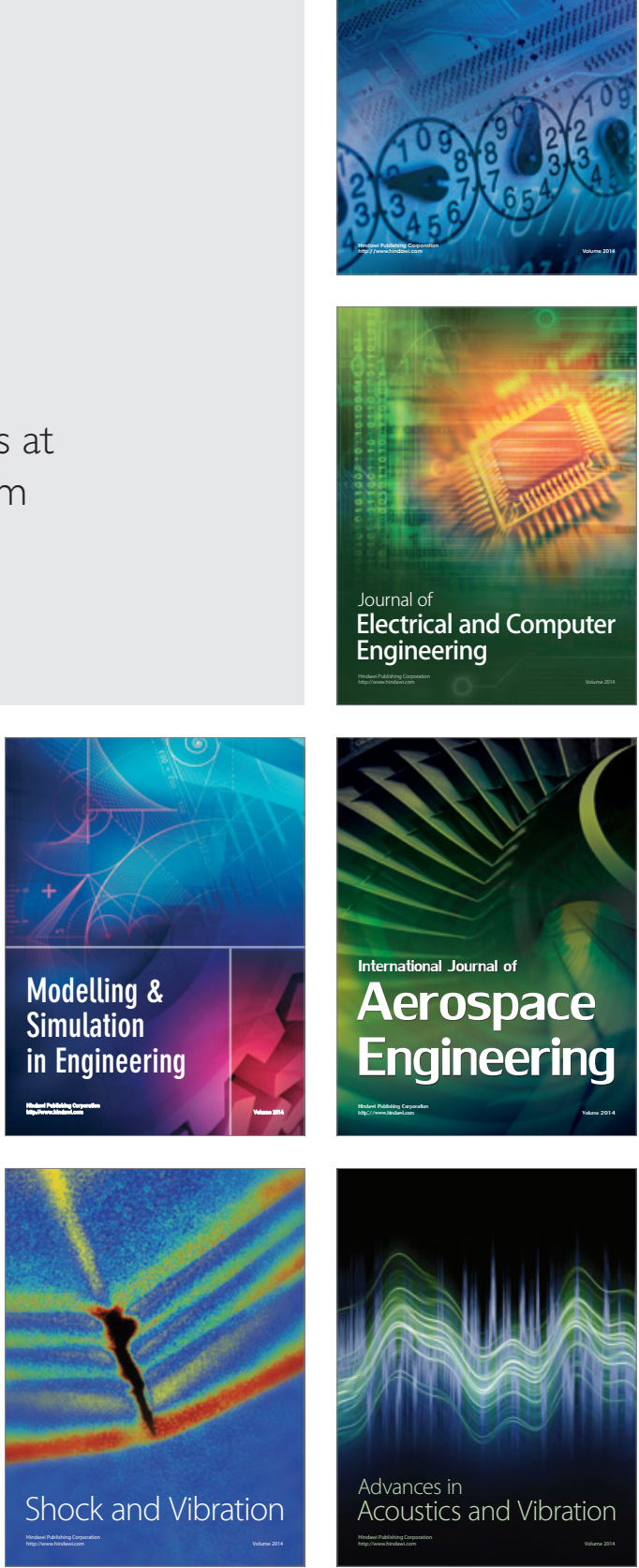